\title{
Optimizing Skip-Stop Rail Transit Stopping Strategy using a Genetic Algorithm
}

\author{
Young-Jae Lee, Ph.D. \\ Morgan State University \\ Shaghayegh Shariat \\ Morgan State University \\ Keechoo Choi, Ph.D. \\ Ajou University
}

\begin{abstract}
With skip-stop rail transit operation, transit agencies can reduce their operating costs and fleet size and passengers can experience reduced in-transit travel times without extra track and technological improvement. However, since skip-stop operation does not serve all stations, passengers for certain origins-destinations could experience increased access time, waiting time, total travel time, and/or transfer. Only when the stopping and skipping stations are carefully coordinated can skipstop service benefit passengers and transit agencies.

This research developed a mathematical model using a Genetic Algorithm that coordinated the stopping and skipping stations for skip-stop rail operation. Using the flexibility of a Genetic Algorithm, this model included many realistic conditions, such as different access modes, different stopping scenarios, different collision constraints, and different objective functions. Passengers were put into three types and nine groups depending on their origin-destination pairs and the station and transfer
\end{abstract}


choices. Four types of collision constraints were developed depending on the skipstop strategy.

For this research, Seoul Metro system Line No. 4 was used as an example. With skipstop operation, total travel time became about 17-20 percent shorter than with original all-stop operation, depending on the stopping constraints. In-vehicle travel time became about 20-26 percent shorter due to skipping stations, although waiting, transfer, and additional access times increased by 24-38 percent.

\section{Introduction}

Both transit agencies and passengers can benefit from increased transit operating speed; in particular, passengers can enjoy shortened travel time. Transit agencies can benefit from accelerated rail transit operation's shorter cycle time, which, consequently, lowers operating costs and reduces fleet size. If a transit agency decides to keep the same fleet size and the same operating costs, then it can increase service frequencies. Eventually, all these advantages can attract more passengers and increase the agency's revenue.

New technology, new rolling stock, and/or better alignment can increase operating speed; however, they usually require a huge investment. In addition to those hardware upgrades, the accelerated operational scheme can increase operating speed by skipping stations. Although accelerated service can increase operating speed, passenger total travel time may not decrease, as shown in Figure 1. Good selection and coordination of skipping stations are necessary to reduce passenger travel time.

Three operational methods can increase rail transit operating speed without requiring technological investment: express/local service, zonal service, and skipstop service. Despite the potential advantages of these accelerated methods, except for some rail transit lines in New York City and Chicago, most current rail transit in the United States uses local or regular service, which is the all-stop operational scheme. This is often due to operational complexity and the lack of methodology in modeling an optimal operational scheme. Nonetheless, there is considerable interest in combining the regular scheme with different accelerated methods to improve operating speed and efficiency. 


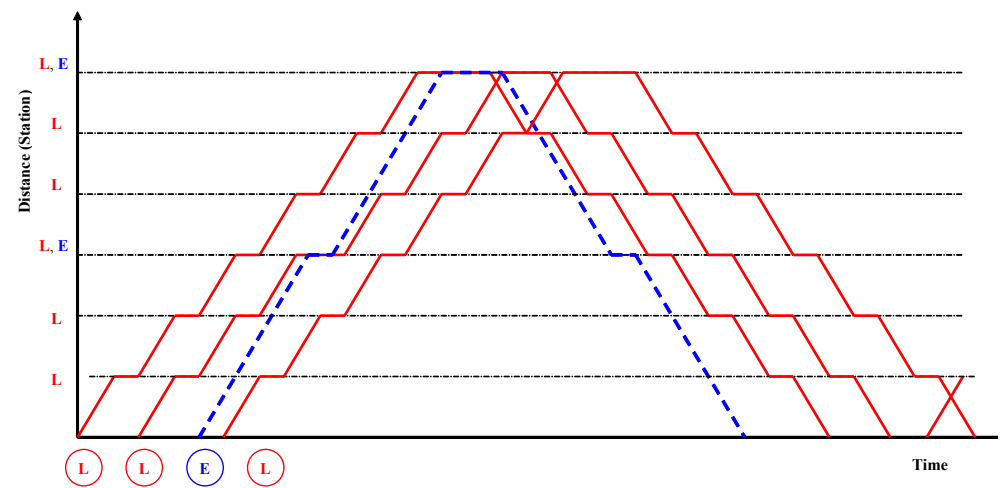

(a) Operational time-distance diagram for express service

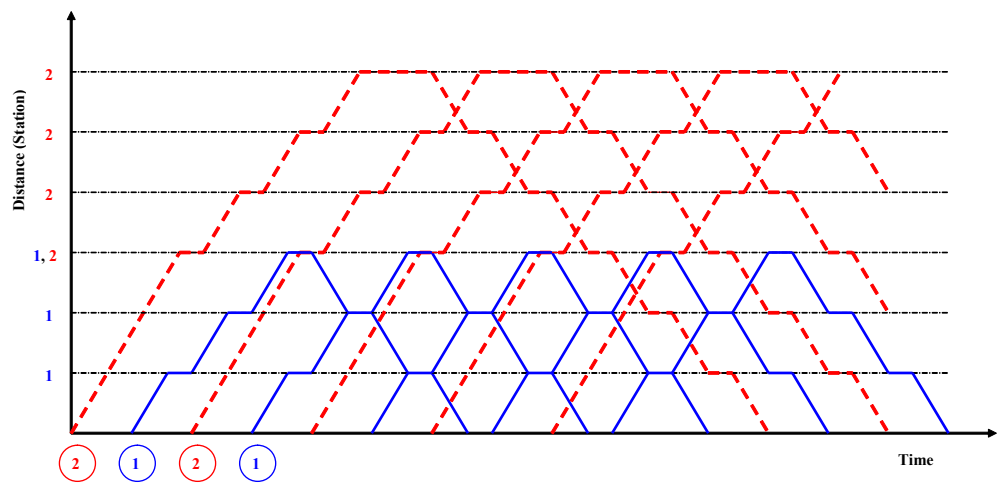

(b) Operational time-distance diagram for zonal service

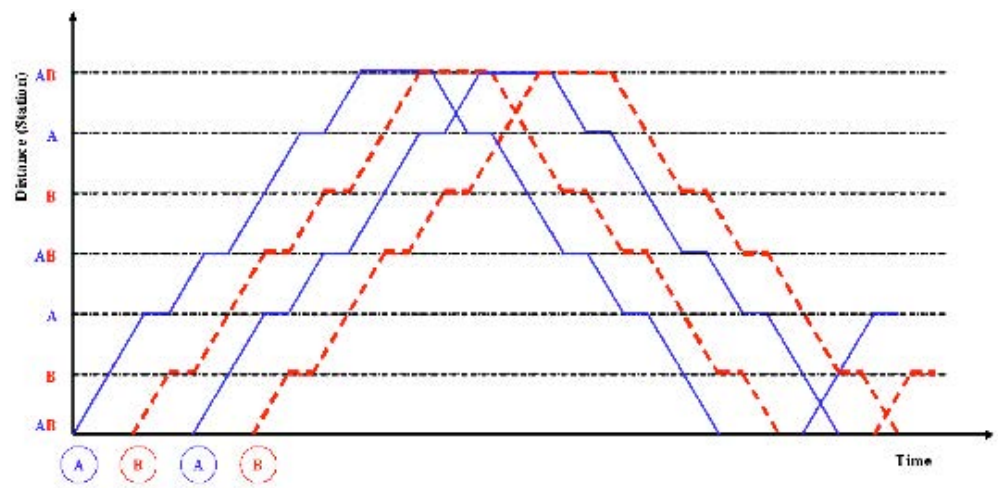

(c) Operational time-distance diagram for alternate stations stopping service Figure 1. Operational time-distance diagram for accelerated rail operation 
Although both express/local service and zonal service do not require technological investment, they require additional track so that express trains can pass local trains, and trains that serve farther zones can pass trains that serve nearer zones (Figures 1a and 1b). Only the skip-stop operation scheme can be implemented without additional track and technological investments, because two different trains-A train and B train-can keep safe separation between trains with proper coordination of stopping stations, as shown in Figure 1c. However, since the trains do not stop at all stations, passengers at skipped stations may experience increased access time or waiting time and may experience transfer.

This research found the optimal coordination of skipping and stopping stations mathematically that can increase and improve the overall benefits of the skip-stop operational scheme and minimize its disadvantages. To do so, passenger station and travel choices were closely analyzed. This research used a Genetic Algorithm $(\mathrm{GA})$, which prevents huge potential computational efforts by the all-enumeration method, to find the optimal coordination of the skipping and stopping stations.

\section{Literature Review}

\section{Station-to-Station Travel Time Components (Vuchic 2007)}

Rail transit's station-to-station travel time consists of five components: acceleration, constant speed, coasting, braking, and standing time. Acceleration and braking take more time than travel time with a constant speed for the same distance traveled. If a train can skip a station, it can maintain a constant speed, avoid braking and accelerating, skip standing time, and consequently, reduce its travel time.

The following equations were used to compute acceleration time, accelerating distance, braking time, braking distance, travel time with constant speed, and travel distance with constant speed.

$$
\begin{aligned}
& V=3.6 \cdot a \cdot t_{a} \\
& s_{a}=\frac{a \cdot t_{a}^{2}}{2} \\
& s_{v}=\frac{V \cdot t_{v}}{3.6}
\end{aligned}
$$




$$
\begin{gathered}
V=3.6 \cdot b \cdot t_{b} \\
s_{b}=\frac{a \cdot t_{b}^{2}}{2}
\end{gathered}
$$

where,

$$
\begin{aligned}
& \mathrm{V}=\text { Speed }(\mathrm{km} / \mathrm{h}) \\
& \mathrm{a}=\text { Acceleration rate }\left(\mathrm{m} / \mathrm{sec}^{2}\right) \\
& \mathrm{t}_{\mathrm{a}}=\text { Acceleration time }(\mathrm{sec}) \\
& \mathrm{s}_{\mathrm{a}}=\text { Distance traveled with acceleration }(\mathrm{m}) \\
& \mathrm{t}_{\mathrm{v}}=\text { Time traveled with constant speed }(\mathrm{sec}) \\
& \mathrm{s}_{\mathrm{v}}=\text { Distance traveled with constant speed }(\mathrm{m}) \\
& \mathrm{b}=\text { Braking rate }\left(\mathrm{m} / \mathrm{sec}^{2}\right) \\
& \mathrm{t}_{\mathrm{a}}=\text { Braking time }(\mathrm{sec}) \\
& \mathrm{s}_{\mathrm{a}}=\text { Distance traveled while braking }(\mathrm{m})
\end{aligned}
$$

\section{Accelerated Rail Service (Vuchic 2005)}

Although accelerated rail operation provides many benefits to users and operators, accelerated rail transit operational schemes may not be implemented with the existing two tracks. As shown in Figures $1 \mathrm{a}$ and $1 \mathrm{~b}$, express and zonal services require a third track (at or between the stations) so that the following train can pass the previous train.

However, as shown in the Figure 1c, skip-stop operation can be implemented without additional track when stopping stations are properly coordinated. Although the distance between two consecutive trains can be narrower at certain sections, they do not collide unless the headway is shorter than a technical minimum headway plus time savings by skipping a station.

\section{Skip-Stop Operation}

Skip-stop operation can increase operating speed and, consequently, it reduces passenger in-vehicle travel time and the rail transit cycle time. Reduced cycle time 
also decreases the number of trains and operating costs. However, since the trains do not stop at all stations, passengers at skipped stations may experience additional access/egress time and/or increased waiting time. Also, they may experience transfer if they want to avoid additional access/egress time. Because of these tradeoffs, only well-coordinated skip-stop stations can reduce user total travel time and total society costs eventually.

Because of the difficulty in selecting skipping and stopping stations and the complexity of the skip-stop operation, only a few rail systems use skip-stop operation, such as J/Z line in New York City Transit and the rail system in Santiago, Chile. However, there have been no rigorous efforts to optimize skip-stop operation, and most research has been based on empirical analysis.

Suh et al. (2007) evaluated the effects of skip-stop operation using the Korean Subway system as a case study. Although this study tried various operational scenarios to determine the most efficient operational strategy, it was based on predetermined sets of skipping and stopping stations as well as predetermined sets of operational scenarios. This research developed a methodology for evaluating the given sets of skip-stop operational strategies; however, it was developed empirically, not mathematically,

Zheng et al. (2009) developed an optimization model for the skip-stop strategy to minimize total travel time using a Tabu search algorithm. Although the model considered the trade-off between in-vehicle travel time and waiting time of passengers, the model did not include two other major disadvantages of skip-stop operation-additional access and egress times and transfer time, which are essential elements for the model because they occur for some passengers, depending on coordination of skipping and stopping stations and passenger choices.

Some research has studied skip-stop services for bus operation, including Niu (2011), who proposed bilevel GA-based skip-stop scheduling for a congested transit case, in which the outer GA searches the departure time and the inner GA skip-stop operations. However, the nature of rail transit operations and bus transit operations are very different, and rail transit operation requires many more constraints regarding collision and safety. As a result of the literature review, it was confirmed that there have been no rigorous efforts to optimize skip-stop operation and the sequence of skipping and stopping stations. 


\section{Genetic Algorithm}

A Genetic Algorithm (GA) is a heuristic search method that imitates the process of natural evolution. It is motivated by the principles of natural selection and survivalof-the-fittest individuals (J. C. Jong 1998). This method is commonly used to generate useful solutions to optimization problems. There is now considerable evidence that GAs are useful for global function optimization and NP-hard problems despite continuous arguments.

The common benefit of a GA is its capability to improve the internal knowledge of an environment. This corresponds to a clear understanding of the possible structural changes and the legal operators for selecting and making changes.

In GAs, the problem is treated as the environment, and a set of possible solutions is treated as the population. In evolution, a child inherits good features from its parents via gene recombination or mutation. In GAs, recombination and mutation play key roles in the search space (K. D. Jong 1998).

Initially, the process starts by generating random individuals from the entire range of possible solutions (the search space) to form an initial population. The population size depends on the nature of the problem. Each individual in the population is represented by an encoded solution, called a chromosome. The individuals then compete with each other to produce children. In each generation, the fitness of every individual in the population is evaluated. Individuals are selected from the current population based on their fitness, recombined, and randomly mutated to form a new population. The new population is used in the next iteration of the algorithm (Goldberg 1989).

The process stops when a terminating condition is reached. This condition could be defined based on the nature of the problem. Some common terminating conditions include the following: a solution is found that satisfies the minimum criteria; a fixed number of generations is reached; the allocated budget (computation time/ money) is reached; the highest-ranking solution's fitness is reaching (or has reached) a level such that successive iterations would not produce better results; or a combination of those conditions is achieved (Goldberg 1989).

\section{Methodology}

This research considers skip-stop operation as a choice for an accelerated rail transit operational scheme since it does not require additional track. Trains using this scheme increase their speed by skipping stations. However, to minimize 
inconveniences for passengers due to skipping stations, stopping stations must be selected properly and coordinated carefully.

To find the best coordination of stopping stations, this research developed the optimization process. The optimization process includes four main componentsobjective function, constraints, cost estimation, and GA-to generate potential solutions.

This research uses a GA for searching a near-optimal solution, because the allenumeration method requires huge computations $\left(3^{X}\right.$, where $X$ is the number of stations). Like a general GA, generated solutions are evaluated and compared using the fitness test with the previous optimal solutions. Then, the process keeps searching for the better solution until there is no better solution or until the algorithm reaches the given number of iterations, as shown in Figure 2.

Variables such as origin-destination (O-D) demand data, station-to-station distances, access modes, access times, etc., are needed to estimate user travel time. The mathematical model in this research will use those variables as inputs for the model, and the results of the model will show the best coordination of stopping stations to minimize the objective function and travel time estimation.

\section{Optimization Process Using a GA}

To use a GA for optimization, the concepts of genes and chromosomes and their fitness should be defined. In this project, chromosomes are the stations and Matrix $S$ is the gene containing the station types ( $A, B$, or $A B$ chromosomes). The fitness of each gene is estimated based on the objective function. The objective function in this project is the total travel time. It is based on the developed models for calculating the total travel time, which is the fitness of Matrix S. Figure 2 presents the overall view of the optimization process in this project using a GA, and Table 1 shows the operators used to generate the children for the GA in this research. 


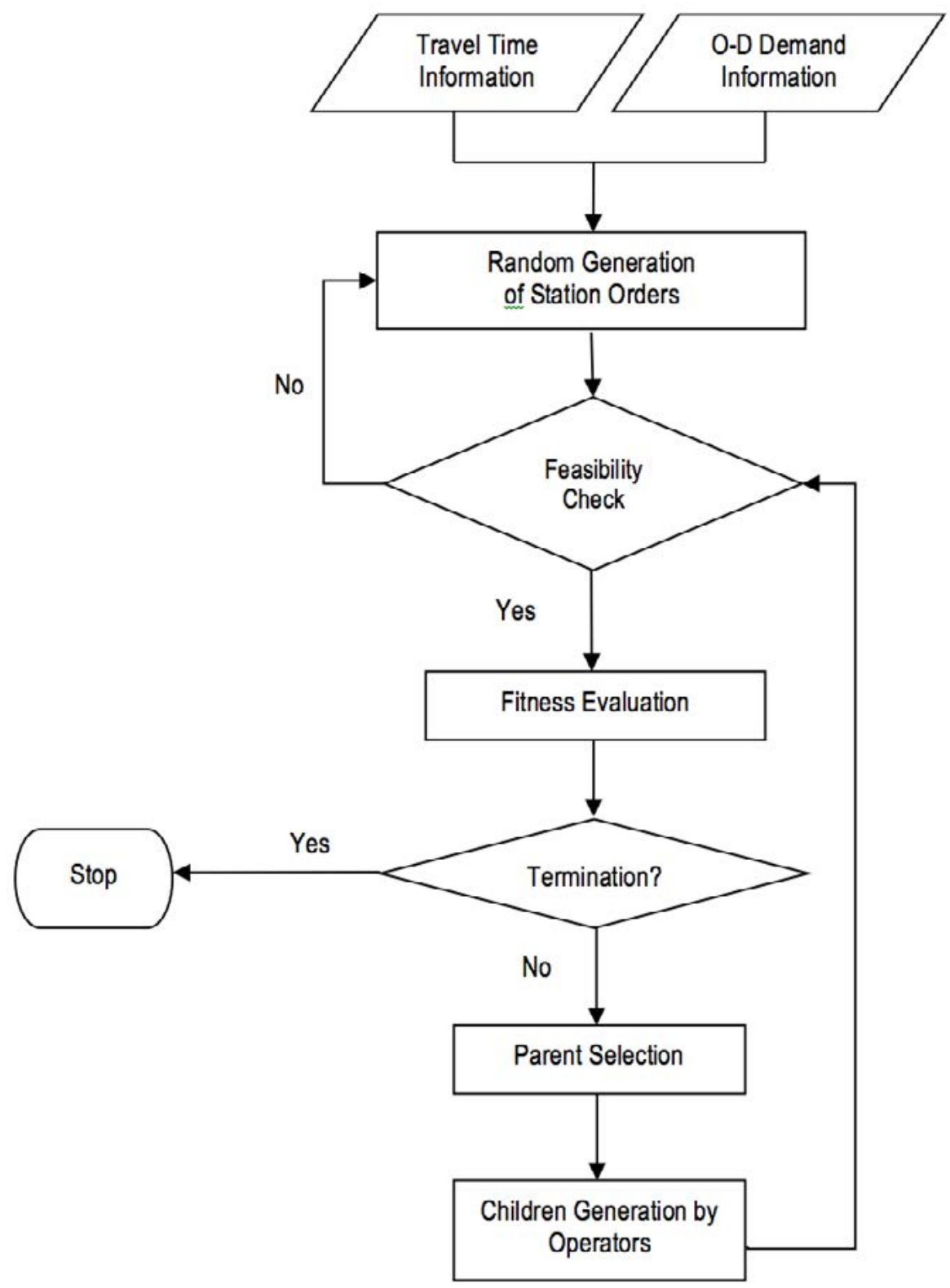

Figure 2. Overall procedure for finding an optimal solution 


\section{Table 1. Operators for GA Used in this Model}

\begin{tabular}{|c|c|c|c|}
\hline & Type & Explanation & Figure \\
\hline 1 & Crossover & $\begin{array}{l}\text { Creates child that inherits odd cells from } \\
\text { Father and even cells from Mother }\end{array}$ & $\mathbb{E}$ \\
\hline 2 & Crossover & $\begin{array}{l}\text { Creates child that inherits even cells from } \\
\text { Father and odd cells from Mother }\end{array}$ & $\Delta$ \\
\hline 3 & $\begin{array}{l}\text { Customized } \\
\text { crossover }\end{array}$ & $\begin{array}{l}\text { Creates child that inherits best genes } \\
(40 \%) \text { from Mother and others from } \\
\text { Father }\end{array}$ & सM. \\
\hline 4 & $\begin{array}{l}\text { Customized } \\
\text { crossover }\end{array}$ & $\begin{array}{l}\text { Creates child that inherits best genes } \\
(40 \%) \text { from Father and } \\
\text { others from Mother }\end{array}$ & परा \\
\hline 5 & $\begin{array}{l}\text { Customized } \\
\text { crossover }\end{array}$ & $\begin{array}{l}\text { Creates child in which worst genes ( } 40 \%) \\
\text { from Father are omitted and replaced by } \\
\text { Mother gene }\end{array}$ & \\
\hline 6 & $\begin{array}{l}\text { Customized } \\
\text { crossover }\end{array}$ & $\begin{array}{l}\text { Creates child in which worst genes ( } 40 \%) \\
\text { from Mother are omitted and replaced by } \\
\text { Father gene }\end{array}$ & N \\
\hline 7 & $\begin{array}{l}\text { Combined } \\
\text { crossover and } \\
\text { mutation }\end{array}$ & $\begin{array}{l}\text { Creates child that inherits best Mother } \\
\text { and Father genes ( } 40 \% \text { each) and other } \\
\text { genes are random }\end{array}$ & \\
\hline 8 & $\begin{array}{l}\text { Combined } \\
\text { crossover and } \\
\text { mutation }\end{array}$ & $\begin{array}{l}\text { Creates child in which worst genes ( } 40 \% \\
\text { each) from Mother replaced by Father } \\
\text { and worst genes from Father replaced by } \\
\text { Mother; other genes replaced randomly }\end{array}$ & NWa \\
\hline 9 & $\begin{array}{l}\text { Whole non- } \\
\text { uniform } \\
\text { mutation }\end{array}$ & $\begin{array}{l}\text { Creates child that inherits random } \\
\text { genes (maintaining diversity of genes in } \\
\text { population) }\end{array}$ & $\mathbb{8}$ \\
\hline 10 & Mother saver & $\begin{array}{l}\text { Creates child that inherits all Mother } \\
\text { genes (replacing Mother in new } \\
\text { generation) }\end{array}$ & TNa \\
\hline 11 & Father saver & $\begin{array}{l}\text { Creates child that inherits all Father genes } \\
\text { (replacing Father in new generation) }\end{array}$ & WNNAN \\
\hline
\end{tabular}

For this particular optimization model, in addition to the general operators for the GA, customized crossover operators were designed to find the optimal solution more efficiently, which are types 3-6 in Table 1. Since it is important to keep the better O-D pairs together (instead of as a single chromosome), the better 40 percent of chromosome pairs were kept and others were replaced with operators 3 and 4 . In addition, the worse 40 percent of chromosome pairs were replaced with operators 5 and 6 . The 40 percent comes from experiments with different numbers 
in this research; however, it will be necessary to find the optimal number in a future study.

\section{Objective Function}

There can be three types of objective functions: user travel-time minimization, operator benefit maximization, and total cost minimization.

As mentioned, well-coordinated skip-stop operation reduces in-vehicle travel time for users and increases operating speed for operators. However, some users will experience increased waiting time, access time, egress time, and, possibly, transfer time. Thus, there is no guarantee that skip-stop operation will reduce the total travel time of all users.

The selection and coordination of stopping stations can be done based on the objective function. If the objective function is user travel-time minimization, the proper selection and coordination of stopping stations will minimize the total travel time of all users, including their in-vehicle travel time, access time, egress time, waiting time, and transfer time.

Skip-stop service always increases operating speed, which results in reduced operator costs and fleet size. However, it does not mean that this service always produces advantages for operators. If passenger total travel time increases because of bad coordination of skip-stop stations, fewer people will use the transit service and transit agencies will lose revenue. Since operator benefit consists of operator reduced costs and increased revenue, under the objective function of operator benefit maximization, the selection and coordination of stopping stations will maximize the operator benefit, which is the difference between operator revenue and costs.

The last possible objective function is minimization of total costs, including user travel time and operator costs. The selection and coordination of stopping stations can be developed to minimize total costs.

In this research, user travel-time minimization was used; however, in future research, other objective functions can be applied, and the results of the different objectives can be compared and evaluated. Also, a combination of different objective functions for different times of the day, such as minimizing travel time for peak hours and maximizing revenue for off-peak hours, can be examined. 


\section{Cost Estimation (Fitness)}

The mathematical model estimates passenger total travel time through coordination of stopping stations, which is also the objective function of the model. Each passenger's total travel time, which includes access time, waiting time, in-vehicle travel time, transfer time, and egress time, is formulated for each selection of the stopping stations. As a result, the model will suggest the best coordination of the stopping stations for the skip-stop operation strategy.

\section{Three Types of O-D Pairs}

For skip-stop operation, stations were categorized as Stations $A, B$, and $A B$. The $A$ trains stop at $A$ stations and $A B$ stations, and the $B$ trains stop at $B$ stations and $A B$ stations. Consequently, O-D trips are categorized into nine groups, such as $A-A$, $A-B, A-A B, B-A, B-B, B-A B, A B-A, A B-B$, and $A B-A B$. If the $O-D$ pair is $A B-A B$, then passengers have the same headway, access, and egress time, while enjoying reduced in-vehicle travel time (Type I in Table 2).

Table 2. Three Types of O-D Trips for Nine O-D Combinations

\begin{tabular}{|c|c|c|c|c|}
\hline OD Type & Orig. & Dest. & Decision & Penalty \\
\hline Type I & $A B$ & $A B$ & Take any coming train. & None \\
\hline \multirow{6}{*}{ Type II } & A & A & Take A train. & $h^{\text {new }}=2 h, w^{\text {new }} \leq 2 w$ \\
\hline & A & $A B$ & Take A train. & $h^{\text {new }}=2 h, w^{\text {new }} \leq 2 \mathrm{w}$ \\
\hline & B & B & Take B train. & $h^{\text {new }}=2 h, w^{\text {new }} \leq 2 w$ \\
\hline & B & $A B$ & Take B train. & $h^{\text {new }}=2 h, w^{\text {new }} \leq 2 \mathrm{w}$ \\
\hline & $A B$ & A & $\begin{array}{l}\text { 1. Wait for } A \text { train. } \\
\text { 2. Take } B \text { train and walk to } A \text { station. }\end{array}$ & $\begin{array}{l}\text { Min }\left\{\left(w^{\text {new }} \leq 2 \mathrm{w}\right) \text { or }\right. \\
\text { (additional egress })\}\end{array}$ \\
\hline & $A B$ & B & $\begin{array}{l}\text { 1. Wait for } B \text { train } \\
\text { 2. Take } A \text { train and walk to } B \text { station }\end{array}$ & $\begin{array}{l}\operatorname{Min}\left\{\left(\mathrm{w}^{\text {new }} \leq 2 \mathrm{w}\right) \text { or }\right. \\
\text { (additional egress })\}\end{array}$ \\
\hline \multirow{2}{*}{ Type III } & A & B & $\begin{array}{l}\text { 1. Take } A \text { train and transfer to } B \text { train at } \\
A B \text { station. } \\
\text { 2. Go to } B \text { station to take } B \text { train. } \\
\text { 3. Take } A \text { train, go to } A \text { station, and walk } \\
\text { to } B \text { station. }\end{array}$ & $\begin{array}{l}\left(\mathrm{w}^{\text {new }} \leq 2 \mathrm{w}\right)+\operatorname{Min}\{\mathrm{Min} \\
\text { (additional access time } \\
\text { or additional egress } \\
\text { time) or transfer time }\}\end{array}$ \\
\hline & B & A & $\begin{array}{l}\text { 1. Take } B \text { train and transfer to } A \text { train at } \\
A B \text { station. } \\
\text { 2. Go to } A \text { station to take } A \text { train. } \\
\text { 3. Take } B \text { train, go to } B \text { station, and walk } \\
\text { to } A \text { station. }\end{array}$ & $\begin{array}{l}\left(\mathrm{w}^{\text {new }} \leq 2 \mathrm{w}\right)+\operatorname{Min}\{\mathrm{Min} \\
\text { (additional access time } \\
\text { or additional egress } \\
\text { time) or transfer time }\}\end{array}$ \\
\hline
\end{tabular}

$h=$ headway, $w$ = waiting time 
If an $O-D$ pair is other than $A B-A B$, then passenger headway will be twice as long as that of the $A B-A B$ passengers because they can take only either an $A$ train or $B$ train, not both. If headway becomes twice as long, then waiting time can be up to twice as long. If there is no scheduling information, then waiting time becomes twice as long. However, if scheduling information is available, then average waiting time can be less than half of the headway because passengers can arrive at stations just before the train arrives.

If the O-D pair is either A-B or B-A, then the passenger will need a transfer to reach the destination station or will need to change the origin or destination station to avoid transfer. Passengers will choose to transfer or change their origin or destination to minimize their travel time depending on their exact origin and destination location (Type III in Table 2). The rest of the cases require headway and waiting time that are up to twice as long (Type II in Table 2).

\section{Reduced Travel Time by Skipping a Station}

The amount of reduced travel time depends on acceleration rate, braking rate, maximum constant speed, operation strategy (e.g., whether there is coasting), dwell time, and the distance between stations. Consequently, computation of the saved time can be complicated and has many variables.

According to transit agencies including Washington Metropolitan Area Transit Authority (WMATA) and Seoul Metropolitan Rapid Transit Corporation (SMRT), acceleration rate and braking rate range from 0.75 to $3 \mathrm{mph}$ per second, and maximum speed ranges from $40-80 \mathrm{mph}$.

Assuming $2 \mathrm{mph}$ per second ( $3.2 \mathrm{~km} / \mathrm{h} / \mathrm{sec}$ ) for acceleration and braking rates, to reach the assumed maximum speed of $60 \mathrm{mph}$ will take 30 seconds while traveling 0.25 miles, according to equations 1 and 2 . From $60 \mathrm{mph}$, it also will take 30 seconds to stop while traveling 0.25 miles according to equations 4 and 5 . Using equation 3 , it will take 15 seconds to travel 0.25 miles with a $60 \mathrm{mph}$ constant speed. As a result, not accelerating and not braking can save 15 seconds each. Standing time is about 30 seconds at each station. Under those assumptions, skipping one station can save a total of one minute. Therefore, this research assumed that one minute is saved each time a train skips one station.

However, this computation is based on the above assumptions, so the real time savings by skipping one station vary by station and operation strategy. If the maximum speed and/or the acceleration rate are lower, then the time saved by skipping one station is less than one minute. 


\section{Transfer}

Type III passengers need to transfer or change their origin or destination station. There are two types of transfers. If the $A B$ station is inside the origin and destination, then passengers can transfer at the $A B$ station and will spend only additional transfer time, which is headway between two trains, in addition to their original travel time. If there is no transfer station, then passengers need to find a transfer station outside the origin and destination. In this case, passengers not only will spend transfer time but also will add in-vehicle time (to go to the transfer station and come back) to their original travel time.

\section{Access Modes and Additional Access Time for Changing Origin or Destination Stations}

There are other concerns in the estimation of the total passenger travel times. The first concern is the access mode to the train station for the Type III passengers. Train users can access stations by foot, car, bicycle, or feeder bus. Depending on their access mode, their additional access time to their origin or destination stations varies, and their decision to transfer or change the origin/destination is based on their additional access time and transfer time.

In this research, two groups-those who walk to the station and those who access it by car or feeder bus-were considered to compute the access time to other origin or destination stations. Since passengers who use park-and-ride, kiss-and-ride, or a feeder bus have a shorter additional access time to the new origin station that does not require transfer to go to their destinations, their average access time to the other origin station will be shorter than passengers who walk to the new origin station. However, the exact amount of additional access time depends on the locations of the origins.

For simplicity, this research assumed that passengers were uniformly distributed throughout the area. When users chose their origin stations, they selected stations that required the shortest total travel time.

Depending on the origin's location, going to the other station increases a different amount of travel time. For the one extreme case, changing an origin station will not increase total travel time at all when passenger origin is equidistant from the two stations. Thus, passengers choose an origin station arbitrarily, and changing the origin station will not add any additional access time.

When the origin is at the station, changing the origin station requires the whole distance traveled from the original station to the new station. The additional access 
distance is the whole distance between the two stations, and the additional travel time is the additional access time to the other station minus station-to-station, in-vehicle travel time. For example, if it takes 15 minutes to walk to the new origin station and station-to-station and in-vehicle travel time is 3 minutes, then the additional access time is 12 minutes. If the access mode is auto and the additional driving time is 4 minutes, then the additional access time is only 1 minute.

Therefore, in the above situation, the minimum additional access time is zero minutes, and the maximum additional access time is 12 minutes by foot or 1 minute by auto. Since uniform distribution of total passengers is assumed, the additional access time is uniformly distributed between minimum additional access time and maximum additional access time. The distribution of walking passengers and driving passengers is a variable for this model, and this distribution rate can be set differently for each O-D pair.

\section{Transferring vs. Changing the Origin or Destination Stations}

For Type III origin-destination pairs, each pair was examined to determine if passengers would take a transfer or change their origin or destination. Access modes and origins determine the additional access times resulting from an origin or a destination change, so their decision between transfer and changing origin/destination can be made based on their additional access time and transfer time.

To estimate the number of passengers who will change their origin station and the number of passengers who will stick to their original station and transfer, the research compared the transfer time and additional access time of Type III passengers. Since transfer time is fixed, regardless of whether the transfer station is inside, outside, or between the origin and destination stations, transfer time was used as a standard. The range of additional access time to the other station that avoids the transfer was estimated based on access modes and passenger origins. Using transfer time and additional access time, it was assumed that passengers would change their origin if a transfer would result in longer travel time, and passengers would stay at their origin and transfer if a transfer would result in shorter travel time.

\section{Different Weights for Travel Time Components}

Total travel time consists of access time, waiting time, in-vehicle travel time, transfer time, and egress time. Although their units are the same, the perception of passengers may vary. Some researchers show that access time, waiting time, transfer time, and egress time can be as costly as three times in-vehicle travel time for the same amount of time (Kittleson \& Associates 2003). 
Although this algorithm can handle different weights for different travel time components, the same time value for all travel time components was applied to this example to show the absolute time amount for each travel time component and show how the trade-off between travel time components works.

\section{Planning Horizon}

The other concern is continuous transit operation during the day. The optimal solution for a certain period, such as morning peak, is not necessarily the optimal solution for a whole day or whole week. To make the precise evaluation, O-D demand for each hour and each hour's headway must be available. However, for simplicity, this research used one peak-hour demand and headway to find the optimal coordination of the stopping stations. Consequently, the result is optimal for that period only. Once the data are available for a whole day, it would not be difficult to find an optimal solution for a day or week.

This research developed a mathematical model that suggested optimal stopping stations for the skip-stop operational scheme. The model considers the nine aforementioned cases to minimize total passenger travel time on the route. Obviously, some passengers will have longer travel times due to longer headway and transfers, but a good selection of the alternate stopping stations can save travel time for more passengers. If a particular route is not suited for the skip-stop operation, then the results will show all stations as $A B$, which means that all trains must stop at all stations. The all-cost estimation process is shown in Figure 3.

\section{Constraints}

The most important constraint in this algorithm is the avoidance of collisions between the two trains. Unlike regular service, in which trains stop at all stations, skip-stop operation allows trains to skip stations. Once a train skips a station, its distance from the preceding train, which stops and skips at different stations, becomes shorter. Since two trains should not collide, this constraint is critical. In this study, for two trains to avoid collision, four scenarios were suggested based on the rules for stopping stations and initial headways in Table 3. 


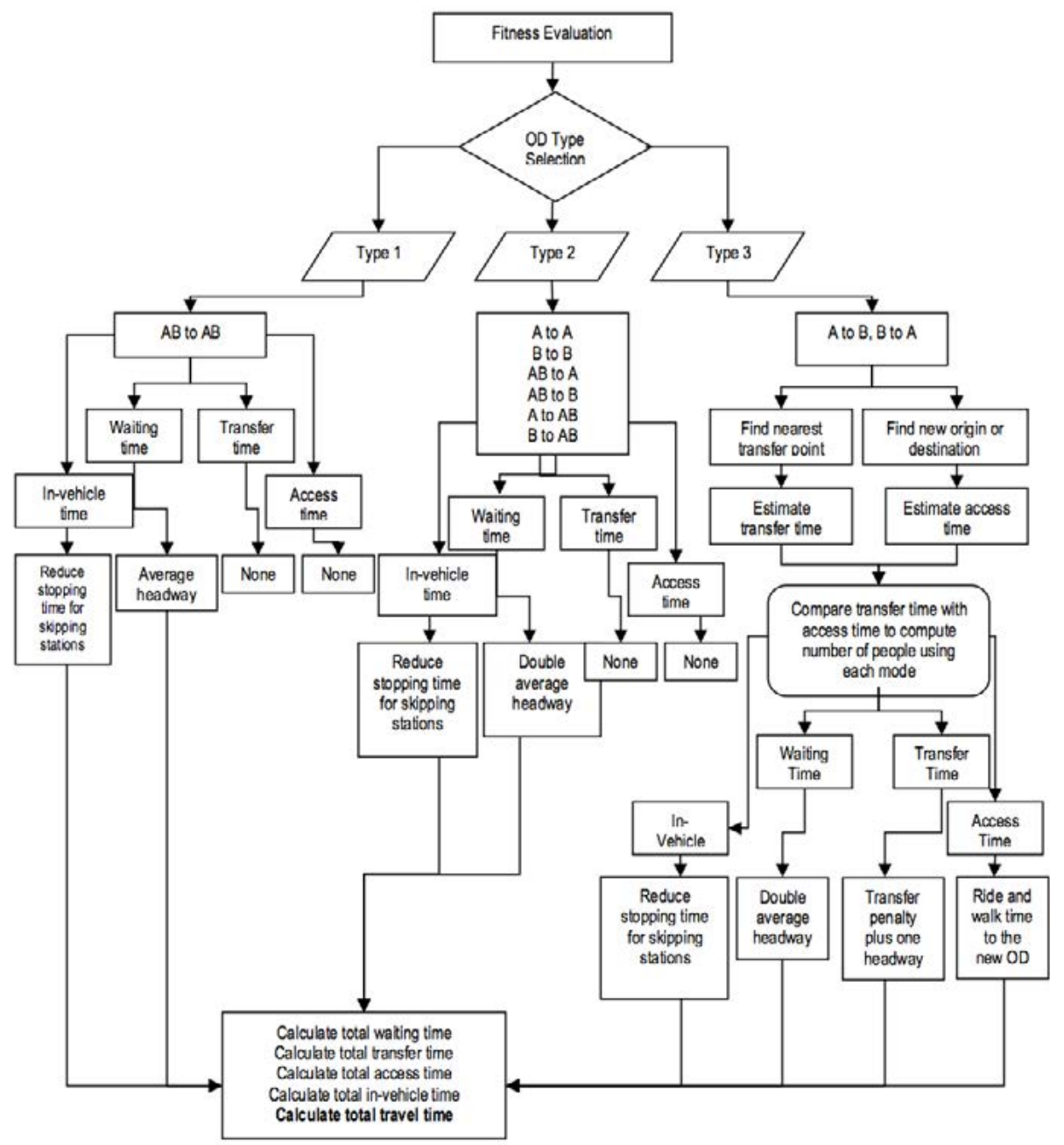

Figure 3. Fitness evaluation process 


\section{Table 3. Four Types of Collision Constraints}

\begin{tabular}{|c|c|c|}
\hline $\begin{array}{l}\text { Collision } \\
\text { Constraints }\end{array}$ & Definition & Constraints \\
\hline Scenario I & $\begin{array}{l}\text { Different type of exclusive } \\
\text { stopping station between } \\
\text { exclusive stopping stations }\end{array}$ & $\begin{array}{l}-1 \leq\left(\sum \mathrm{CIS}_{\mathrm{i}} \times \text { saving time by skipping }\right) \leq 1, \\
\text { (Headway - Saving time by skipping) } \geq \text { Safety } \\
\text { gap time }\end{array}$ \\
\hline Scenario II & $\begin{array}{l}\text { No consecutive same type of } \\
\text { exclusive stopping stations }\end{array}$ & $\begin{array}{l}-2<\left(\mathrm{CIS}_{\mathrm{i}}-\mathrm{CIS}_{\mathrm{i}-1}\right)+\left(\mathrm{CIS}_{\mathrm{i}+1}-\mathrm{CIS}_{\mathrm{i}}\right)<2,-(\text { Headway } \\
- \text { Safety gap }) \leq\left(\sum \mathrm{CIS}_{\mathrm{i}} \times \text { Saving time by skipping }\right) \\
\leq(\text { Headway - Safety gap })\end{array}$ \\
\hline Scenario III & $\begin{array}{l}\text { Uniform headway between } \\
\text { different types of trains }\end{array}$ & $\begin{array}{l}-(\text { Headway }- \text { Safety gap }) \leq\left(\Sigma \mathrm{CIS}_{\mathrm{i}} \times \text { Saving time }\right. \\
\text { by skipping }) \leq \text { (Headway - Safety gap })\end{array}$ \\
\hline Scenario IV & $\begin{array}{l}\text { Uniform headway between } \\
\text { same type of trains }\end{array}$ & $\begin{array}{l}\operatorname{Min}_{i} \leq\left(\sum C_{1} S_{i} \text { Saving time by skipping }\right) \leq \operatorname{Max}_{i}, \\
\operatorname{Max}_{i} \leq 2 \times(\text { Headway }- \text { Safety gap }), \operatorname{Min}_{i} \geq-2 \\
\left.\text { x (Headway - Safety gap), (Max }{ }_{i}-\operatorname{Min}_{i}\right) \leq 2 \times \\
\text { (Headway - Safety gap) }\end{array}$ \\
\hline
\end{tabular}

CIS: Collision Index Score

Scenario I has the most restricted constraint, as it provides the least number of feasible solutions. The constraint does not allow two consecutive types of exclusive stations, even if there is a general station between two same types of exclusive stations. For example, the A-AB-A combination is not allowed; there must be a $B$ station between $A$ stations, even if there is an $A B$ station between them. In other words, after an $A$ station, there must be a B station before an $A$ station is located. Since this scenario requires a different exclusive stopping station between other kinds of stopping stations, users can accept this scenario relatively easily because the distribution of the stations looks uniform. Because no train skips two more stations than the other type of train skips, two different types of trains will not collide as long as the headway is longer than the sum of safety distance between the two trains and the time saved by skipping one station.

However, if the same type of exclusive stopping stations are allowed to repeat whether there is a general station in between them or not, it is necessary to check whether two trains will collide at every station. To check whether the two trains will collide, the arrival times of two different, consecutive trains ( $A$ train and $B$ train) must be checked. If the difference is greater than safety time and standing time, then the two trains can operate without collision. If the difference is less than safety time and standing time, then the two trains will collide and the selection of stopping stations is infeasible. 
Scenario II does not require a different kind of exclusive stopping station between two of the same kind of stopping stations as long as there is a general stopping station between them. As long as there are not two consecutive, same types of stopping stations, this scenario is acceptable. For example, this scenario will allow A-AB-A combination. Since this scenario relaxes the constraint of Scenario I, Scenario II provides more feasible solutions and better results.

Although it does not distribute the stopping stations as uniformly as Scenario I, users can comfortably accept Scenario II because they can easily access different types of stations. For example, if users want to go to the other type of station to catch another type of train because the original station requires transfer, they can go to the adjacent station, which is either another type of station or a general stopping station.

Scenarios III and VI do not restrict the distribution and coordination of stations as long as the coordination of stopping stations prevents collisions. The difference between scenarios III and IV is the initial headway. Scenario III keeps the initial headway between the two different types of trains. Scenario IV keeps the initial headway between the two same types of trains, but not necessarily between two different types of trains (i.e., A-A trains should have the same headway as B-B trains, but headway between $A-B$ trains and $B-A$ trains does not need to be the same).

To consider those four scenarios, " 1 " was assigned to A stations, " 0 " was assigned to $A B$ stations, and " -1 " was assigned to $B$ stations. Then, at each station, the cumulative score from the terminal-called "Collision Index Score"-was used to compute the separation between the two trains. If the number becomes bigger, positively or negatively, one train is going much faster than the other and the chance of collision becomes higher. If headway, safety distance between trains, and time saved by skipping are given, then the feasible area for each collision constraint can be defined (Table 3).

As can be seen, Scenario I has fewer feasible solutions than Scenario II, Scenario II has fewer feasible solutions than Scenario III, and Scenario III has fewer feasible solutions than Scenario IV. Later, the results and time savings from all four scenarios are presented and discussed.

\section{Formulation}

This problem has many "ifs" in the algorithm for different scenarios; thus, it is not a traditional mathematical format, so there is a difficulty in formulation in a simple 
format. The following is the formulation of this problem in a simple format, as discussed in previous sections.

Minimize: $\mathbf{F}(\mathbf{X}(\mathbf{i})), i=1,2, \ldots, n$

$X(i)=\left\{\begin{aligned} 1, i & \left.\equiv A \quad \text { (if Only Train " } A " \text { stops at station } i^{\text {th }}\right) \\ -1, i & \left.\equiv B \quad \text { (if Only Train "B" stops at station } i^{\text {th }}\right) \\ 0, i & \equiv A B\left(\text { if Both Trains " } A " \& \text { " } B \text { " stop at station } i^{\text {th }}\right)\end{aligned}\right.$

$F(X(i))=\sum_{i=1}^{n-1} \sum_{j=i+1}^{n} O D(i, j) . T(i, j)$

$T(i, j)=\operatorname{ITT}(i, j)-S T(i, j)+W T(i)+T T\left(i, s_{t}\right)+A T\left(i, s_{o}\right)+E T\left(s_{d}, j\right)$

Travel time cost estimations based on OD types (I, II, III) are as follows:

Type I (AB-AB) and Type II (A-A , B-B , AB-A , AB-B , A-AB , B-AB)

$$
\begin{aligned}
& T(i, j)=I T T(i, j)-S T(i, j)+W T(i) \\
& A T\left(i, s_{o}\right)=0 \\
& E T\left(s_{d}, j\right)=0 \\
& T T\left(i, s_{t}\right)=0
\end{aligned}
$$

\section{Type III (A-B, B-A)}

$$
\begin{aligned}
& T(i, j)=I T T(i, j)-S T(i, j)+W T(i)+T T\left(i, s_{t}\right)+A T\left(i, s_{o}\right)+E T\left(s_{d}, j\right) \\
& T T\left(i, s_{t}\right)=W T\left(s_{t}\right) * T_{P}\left(i, s_{t}\right) \\
& A T\left(i, s_{o}\right)=\left(\overline{R_{T}\left(i, s_{o}\right)} * R_{P}\left(i, s_{o}\right)\right)+\left(\overline{W_{T}\left(i, s_{o}\right)} * W_{p}\left(i, s_{o}\right)\right) \\
& E T\left(s_{d}, j\right)=\left(\overline{R_{T}\left(i, s_{d}\right)} * R_{P}\left(i, s_{d}\right)\right)+\left(\overline{W_{T}\left(i, s_{d}\right)} * W_{p}\left(i, s_{d}\right)\right) \\
& O_{p}\left(i, s_{o}\right)=W_{p}\left(i, s_{o}\right)+R_{P}\left(i, s_{o}\right) \\
& D_{p}\left(i, s_{d}\right)=W_{p}\left(i, s_{d}\right)+R_{P}\left(i, s_{d}\right) \\
& T_{P}+O_{p}+D_{P}=1
\end{aligned}
$$


Constraints are as follows:

\section{Scenario 1}

$$
\forall i \in n:\left\{\begin{array}{c}
\left|\sum_{i=1}^{n-1} X(i) \cdot S T(i, i+1)\right|-1 \leq 0 \\
H T(i)-S T(i, i+1)-S F(i) \geq 0
\end{array}\right.
$$

\section{Scenario 2}

$$
\forall i \in n:\left\{\begin{array}{c}
\left|\sum_{i=1}^{n-1} X(i) \cdot S T(i, i+1)\right|-(H T(i)-S F(i)) \leq 0 \\
|X(i+1) \cdot S T(i+1, i+2)-X(i-1) \cdot S T(i-1, i-2)|-2<0
\end{array}\right.
$$

\section{Scenario 3}

$$
\forall i \in n:\left\{\left|\sum_{i=1}^{n-1} X(i) \cdot S T(i, i+1)\right|-(H T(i)-S F(i)) \leq 0\right.
$$

\section{Scenario 4}

$$
\forall i \in n:\left\{\begin{array}{c}
\left|\sum_{i=1}^{n-1} X(i) \cdot S T(i, i+1)\right|-(\operatorname{Max}(i)-\operatorname{Min}(i))<0 \\
\operatorname{Max}(i)-2(H T(i)-S F(i)) \leq 0 \\
\operatorname{Min}(i)+2(H T(i)-S F(i)) \geq 0 \\
(\operatorname{Max}(i)-\operatorname{Min}(i))-2(H T(i)-S F(i)) \leq 0
\end{array}\right.
$$

Where:

OD(i,j): Origin-Destination Demand between stations $i^{\text {th }} \& j^{\text {th }}$

ITT(i,j): Initial Travel Time between stations $i^{\text {th }} \& \mathrm{j}^{\text {th }}$ without skipping any station

ST(i,j): Saved (Stopping) Time by skipping certain stations between stations $i^{\text {th }} \& j^{\text {th }}$

HT(i): Headway Time between two consequent trains at station $i^{\text {th }}$

WT(i): Average Waiting Time at station $i^{\text {th }}$ considered as half of the headway time and maximum of 5 minutes

SF(i): Safety Time considered between the two sequential trains at station $\mathrm{i}^{\text {th }}$

$\mathrm{s}_{\mathrm{o}}$ : Closest station to the origin with the identical train to destination 
AT $\left(i, s_{0}\right)$ : Access Time to the station ( $\left.s_{\mathrm{o}}\right)$ with identical train to the destination: $\left(\mathrm{i}<\mathrm{s}_{\mathrm{o}}<<\mathrm{j}, \mathrm{X}\left(\mathrm{s}_{\mathrm{o}}\right)=\mathrm{X}(\mathrm{j})\right)$

$\mathrm{s}_{\mathrm{d}}$ : Closest station to the destination with the identical train to origin $\operatorname{ET}\left(s_{d}, j\right)$ : Egress Time from the station $\left(s_{d}\right)$ with identical train to the origin: $\left(\mathrm{i}<<\mathrm{s}_{\mathrm{d}}<\mathrm{j}, \mathrm{X}\left(\mathrm{s}_{\mathrm{d}}\right)=\mathrm{X}(\mathrm{i})\right.$ )

$s_{t}$ : Transfer station between the origin and destination with stops for both trains

$\mathrm{TT}\left(\mathrm{i}, \mathrm{s}_{\mathrm{t}}\right)$ : Transfer Time required changing the train in the transfer station $\left(\mathrm{s}_{\mathrm{t}}\right):\left(\mathrm{i}<\mathrm{s}_{\mathrm{t}}<\mathrm{j}, \mathrm{X}\left(\mathrm{s}_{\mathrm{t}}\right)=0\right)$

WT $\left(\mathrm{s}_{\mathrm{t}}\right)$ : Waiting Time at station $\left(\mathrm{s}_{\mathrm{t}}\right)$ : WT $\left(\mathrm{s}_{\mathrm{t}}\right)=\operatorname{Min}(1 / 2 \mathrm{HT}(\mathrm{i}), 5)$

$T_{P}\left(i, s_{t}\right)$ : Percentage of OD $(i, j)$ transferring at station $\left(s_{t}\right)$

$\mathrm{O}_{\mathrm{P}}\left(\mathrm{i}, \mathrm{s}_{\mathrm{o}}\right)$ : Percentage of $\mathrm{OD}(\mathrm{i}, \mathrm{j})$ changing their origin to $\left(\mathrm{s}_{\mathrm{o}}\right)$

$D_{p}\left(i, s_{d}\right)$ : Percentage of $O D(i, j)$ changing their destination to $\left(s_{d}\right)$

$\mathrm{R}_{\mathrm{T}}\left(\mathrm{i}, \mathrm{s}_{\mathrm{o}}\right)$ : Average Riding Time to station $\left(\mathrm{s}_{\mathrm{o}}\right.$ )

$R_{P}\left(i, s_{o}\right)$ : Percentage of $O_{P}\left(i, s_{o}\right)$ riding to station $\left(s_{o}\right)$

$\mathrm{W}_{\mathrm{T}}\left(\mathrm{i}, \mathrm{s}_{\mathrm{o}}\right)$ : Average Walking Time to station $\left(\mathrm{s}_{\mathrm{o}}\right)$

$\mathrm{W}_{\mathrm{P}}\left(\mathrm{i}, \mathrm{s}_{\mathrm{o}}\right)$ : Percentage of $\mathrm{O}_{\mathrm{P}}\left(\mathrm{i}, \mathrm{s}_{\mathrm{d}}\right)$ walking to station $\left(\mathrm{s}_{\mathrm{o}}\right)$

$\mathrm{R}_{\mathrm{T}}\left(\mathrm{i}, \mathrm{s}_{\mathrm{d}}\right)$ : Average Riding Time to station $\left(\mathrm{s}_{\mathrm{d}}\right)$

$R_{P}\left(i, s_{d}\right)$ : Percentage of $D_{P}\left(i, s_{d}\right)$ riding to station $\left(s_{d}\right)$

$\mathrm{W}_{\mathrm{T}}\left(\mathrm{i}, \mathrm{s}_{\mathrm{d}}\right)$ : Average Walking Time to station $\left(\mathrm{s}_{\mathrm{d}}\right)$

$W_{P}\left(i, s_{d}\right)$ : Percentage of $D_{P}\left(i, s_{d}\right)$ walking to station $\left(s_{d}\right)$

\section{Example and Results}

After the mathematical model was developed, the real data from Seoul Metro in Korea was applied to see if accelerated service was feasible for that rail transit line. This research selected Seoul Metro's Line No. 4 as an example, which includes the Gwacheon-Ansan line. Korea Railroad serves Line No. 4, which has 48 stations, and the total travel time between the two terminals during the morning peak is 1 hour and 52 minutes, with 2.5-3 minutes of headway. Line No. 4 currently provides local service, zonal service, and express service. Because there were limited data for this model, this example tested only the applicability (or functionality) of skip-stop operation for the metro line, not the actual feasibility. 
To run this model, hourly O-D demand was essential. However, the only available data was monthly O-D demand and each hour's number of boarding and alighting passengers. As a result, it was necessary to manipulate the data to get the hourly O-D demand from the monthly O-D demand and each station's morning peak hourly boarding and alighting ratio. This analysis used the O-D demand from October 2008. The Geum Jung station was missing from the O-D data, so O-D data for only 47 stations was used with 3-minute headway.

The assumptions for the examples were as follows:

- Because standing time at the station is 30 seconds from the schedule, a train can save 1 minute (including acceleration time, deceleration time, and standing time) if it skips 1 station.

- Safety distance between 2 trains is 1 minute.

- Access time to the other station by foot is 6 times longer than rail's in-vehicle travel time.

- Access time by auto or feeder bus is 1.5 times longer than rail's in-vehicle travel time.

- Total passengers are uniformly distributed; accordingly, their additional access time is distributed uniformly between minimum additional access time and maximum additional access time.

- A total of 70 percent of passengers walked to the station, and 30 percent of passengers arrived at the origin station via a car or a feeder bus.

Table 4 shows the four optimal coordinations of stopping stations after 5,000 iterations, in addition to the original all-stop scenario, using different feasibility constraints to avoid collision.

As programmed, Scenario I always has B stations after A stations, even when there are $A B$ stations in between the $A$ and $B$ stations. Scenario II has $A$ station (19th station) after $A$ station (16th station) with no $B$ station between them because there are $A B$ stations (17th and 18th stations) between $A$ stations.

In Scenario III, since skipping a station saves one minute and the safety distance between two trains is one minute, skipping two stations is allowed when two different types of trains have uniform headway under the three-minute headway assumption. If one type of train skipped two stations, then the other type of train can skip as many as four stations before the previous train skips another station. 
Table 4. Coordination of Skipping and Stopping Stations

\begin{tabular}{|c|c|c|c|c|c|}
\hline Station/Scenario & Original & I & II & III & IV \\
\hline 1 & $\mathrm{AB}$ & $A B$ & $\mathrm{AB}$ & $A B$ & $A B$ \\
\hline 2 & $A B$ & $A B$ & $\mathrm{AB}$ & $A B$ & $A B$ \\
\hline 3 & $A B$ & $A B$ & $A B$ & $A B$ & $A B$ \\
\hline 4 & $A B$ & $A B$ & $\mathrm{AB}$ & B & $A B$ \\
\hline 5 & $A B$ & $A B$ & $A B$ & $A B$ & $A B$ \\
\hline 6 & $\mathrm{AB}$ & $\mathrm{AB}$ & $\mathrm{AB}$ & $\mathrm{AB}$ & $\mathrm{AB}$ \\
\hline 7 & $\mathrm{AB}$ & B & $\mathrm{B}$ & $\mathrm{A}$ & $\mathrm{AB}$ \\
\hline 8 & $\mathrm{AB}$ & $A B$ & $\mathrm{AB}$ & $A B$ & $A B$ \\
\hline 9 & $A B$ & A & A & A & B \\
\hline 10 & $\mathrm{AB}$ & B & B & B & $\mathrm{B}$ \\
\hline 11 & $\mathrm{AB}$ & A & A & B & B \\
\hline 12 & $\mathrm{AB}$ & B & B & A & B \\
\hline 13 & $\mathrm{AB}$ & A & $\mathrm{A}$ & A & $\mathrm{A}$ \\
\hline 14 & $A B$ & B & B & A & B \\
\hline 15 & $\mathrm{AB}$ & $\mathrm{AB}$ & $\mathrm{AB}$ & $\mathrm{AB}$ & $A B$ \\
\hline 16 & $A B$ & $A B$ & A & $A B$ & $A B$ \\
\hline 17 & $\mathrm{AB}$ & $A B$ & $\mathrm{AB}$ & $A B$ & A \\
\hline 18 & $\mathrm{AB}$ & $A B$ & $\mathrm{AB}$ & $\mathrm{AB}$ & $A B$ \\
\hline 19 & $\mathrm{AB}$ & $\mathrm{AB}$ & A & $\mathrm{AB}$ & $A B$ \\
\hline 20 & $A B$ & $A B$ & B & $A B$ & $A B$ \\
\hline 21 & $\mathrm{AB}$ & $A B$ & $\mathrm{AB}$ & $A B$ & $A B$ \\
\hline 22 & $\mathrm{AB}$ & $A B$ & B & $\mathrm{AB}$ & A \\
\hline 23 & $\mathrm{AB}$ & $A B$ & $\mathrm{AB}$ & B & B \\
\hline 24 & $\mathrm{AB}$ & $\mathrm{A}$ & $\mathrm{AB}$ & $\mathrm{AB}$ & A \\
\hline 25 & $A B$ & $A B$ & A & $A B$ & B \\
\hline 26 & $\mathrm{AB}$ & $\mathrm{AB}$ & B & $\mathrm{AB}$ & B \\
\hline 27 & $A B$ & B & $\mathrm{AB}$ & $A B$ & A \\
\hline 28 & $\mathrm{AB}$ & A & $\mathrm{AB}$ & $A B$ & B \\
\hline 29 & $A B$ & $A B$ & $\mathrm{AB}$ & $A B$ & $A B$ \\
\hline 30 & $\mathrm{AB}$ & $\mathrm{AB}$ & A & B & $A B$ \\
\hline 31 & $A B$ & $A B$ & $\mathrm{AB}$ & $A B$ & $A B$ \\
\hline 32 & $\mathrm{AB}$ & $A B$ & $\mathrm{AB}$ & B & $A B$ \\
\hline 33 & $\mathrm{AB}$ & $\mathrm{AB}$ & $\mathrm{AB}$ & $\mathrm{AB}$ & $\mathrm{AB}$ \\
\hline 34 & $A B$ & $A B$ & $\mathrm{AB}$ & $A B$ & $A B$ \\
\hline 35 & $\mathrm{AB}$ & $\mathrm{AB}$ & $\mathrm{AB}$ & $\mathrm{A}$ & $A B$ \\
\hline 36 & $A B$ & $A B$ & $\mathrm{AB}$ & $A B$ & $A B$ \\
\hline 37 & $\mathrm{AB}$ & $\mathrm{AB}$ & $\mathrm{AB}$ & $\mathrm{AB}$ & $A B$ \\
\hline 38 & $A B$ & B & A & B & $A B$ \\
\hline 39 & $\mathrm{AB}$ & $\mathrm{AB}$ & $\mathrm{AB}$ & $\mathrm{AB}$ & $A B$ \\
\hline 40 & $\mathrm{AB}$ & $A B$ & $\mathrm{AB}$ & B & $A B$ \\
\hline 41 & $\mathrm{AB}$ & $A B$ & $\mathrm{AB}$ & $A B$ & $A B$ \\
\hline 42 & $\mathrm{AB}$ & $\mathrm{AB}$ & B & A & $A B$ \\
\hline 43 & $\mathrm{AB}$ & $A B$ & $\mathrm{AB}$ & B & $A B$ \\
\hline 44 & $\mathrm{AB}$ & $\mathrm{AB}$ & $\mathrm{AB}$ & $\mathrm{AB}$ & $\mathrm{AB}$ \\
\hline 45 & $\mathrm{AB}$ & $\mathrm{A}$ & $\mathrm{AB}$ & $\mathrm{AB}$ & $A B$ \\
\hline 46 & $\mathrm{AB}$ & $\mathrm{AB}$ & $\mathrm{AB}$ & $\mathrm{A}$ & $A B$ \\
\hline 47 & $\mathrm{AB}$ & $A B$ & $\mathrm{AB}$ & $A B$ & $A B$ \\
\hline
\end{tabular}


In this example, stations from 12th station to 14th station were allocated as A stations, because before 12th station, there was one more B station than A station from the terminal.

Scenario IV does not require uniform headway between the $A$ and $B$ trains. As a result, the headway between $A$ and $B$ trains can be as long as five minutes. (The five-minute figure is based on the six-minute headway between two $A$ trains minus the one-minute safety distance between $A$ and $B$ trains.) Since the maximum allowable headway between $A$ and $B$ trains is five minutes, the maximum number of consecutive $A$ stations is four, which is five-minute headway minus one minute of the safety distance. In this example, stations from the 9th station and 12th station are all $B$ stations. To make this service safe and feasible, the headway between the $B$ and $A$ trains should be five minutes, and headway between $A$ and $B$ trains should be one minute. For feasibility and safety, the cumulative number of $A$ stations at any station will not be more than that of B stations.

In this example, the results of all four scenarios met the programming constraints.

Table 5 shows the total in-vehicle travel time, total waiting time, total transfer time, and total additional access and egress time for all four cases with the original all-stop case. As can be seen, total travel time becomes shorter with more relaxed constraints.

Table 5. Travel Time Characteristics of Skip-Stop Operation

\begin{tabular}{|l|c|c|c|c|c|}
\hline Scenario & Original & I & II & III & IV \\
\hline $\begin{array}{l}\text { Number of AB } \\
\text { stations }\end{array}$ & 47 & 35 & 31 & 30 & 33 \\
\hline Number of A stations & 0 & 6 & 8 & 8 & 5 \\
\hline Number of B stations & 0 & 6 & 8 & 9 & 9 \\
\hline In-Vehicle Time (min) & $3,688,169.62$ & $2,946,771.66$ & $2,929,213.27$ & $2,847,704.26$ & $2,811,122.13$ \\
\hline Waiting Time (min) & $272,744.43$ & $334,290.85$ & $342,502.14$ & $367,530.57$ & $327,646.25$ \\
\hline Transfer Time (min) & 0.00 & $1,935.99$ & $3,185.69$ & $6,032.21$ & $2,144.89$ \\
\hline $\begin{array}{l}\text { Additional Access/ } \\
\text { Egress Time (min) }\end{array}$ & 0.00 & $1,256.20$ & $1,955.11$ & $3,486.26$ & $1,268.45$ \\
\hline $\begin{array}{l}\text { Total Travel Time } \\
\text { (min) }\end{array}$ & $3,960,914.05$ & $3,284,254.71$ & $3,276,856.22$ & $3,224,753.29$ & $3,142,181.72$ \\
\hline $\begin{array}{l}\text { Average Total Travel } \\
\text { Time (min) }\end{array}$ & 21.78 & 18.06 & 18.02 & 17.73 & 17.28 \\
\hline $\begin{array}{l}\text { Travel Time } \\
\text { Reduction (min) }\end{array}$ & - & $-17.08 \%$ & $-17.26 \%$ & $-18.60 \%$ & $-20.66 \%$ \\
\hline
\end{tabular}


In this example, 181,830 passengers traveled during the one-hour morning peak, and their average total travel time with the original all-stop operation was 21.78 minutes. With skip-stop operation, depending on the stopping constraints, their total travel time became 17-20 percent shorter than that with original all-stop operation. While in-vehicle travel time became 20-26 percent shorter due to skipping stations, waiting time, transfer time, and additional access time were 24-38 percent longer.

Each train skipped 5-9 stations, which reduced 5-9 minutes (up to 8\%) in operating time. As mentioned, this model was built to minimize the total travel time. If the objective of the model was minimization of operating time or total cost, the model could reduce operating time further.

Figure 4 shows the convergence of the searching process for all four scenarios. Except in the Scenario IV case, optimal results converged relatively quickly (about 100,300 , and 600 iterations). Only Scenario IV case took about 2,000 iterations to be converged.

\section{Conclusions}

Well-coordinated skip-stop service can reduce passenger total travel time and improve overall service, since it can increase operating speed. However, the selection and coordination of stopping and skipping stations requires extensive effort since it is a very large combinatorial problem.

This research showed how the optimization process for the selection and coordination of the stopping and skipping stations could be pursued. As discussed, this model used a Genetic Algorithm, which can handle different objective functions and include different constraints for preventing a collision. This model also considered different access modes, as well as different passenger options and choices (including access modes) when the same train does not serve the origin and destination stations. Passengers were put into three types and nine groups depending on their O-D and skip-stop strategy. Also, four types of collision constraints were developed depending on the skip-stop strategy. Since this model considered those components, the results were more realistic.

In this example, 181,830 passengers traveled for one-hour during the morning peak, and their average total travel time with the original all-stop operation was 21.78 minutes. With skip-stop operation, depending on the stopping constraints, their total travel time became about 17-20 percent shorter than that with the origi- 


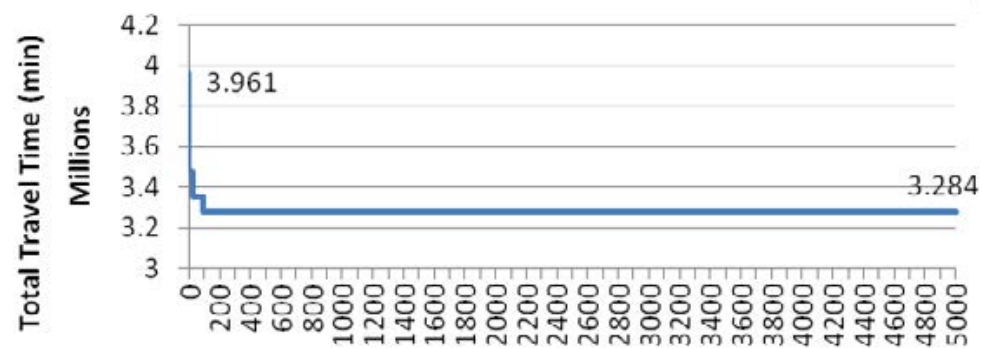

(a)

Fitness trends for Scenario I

Number of iterations

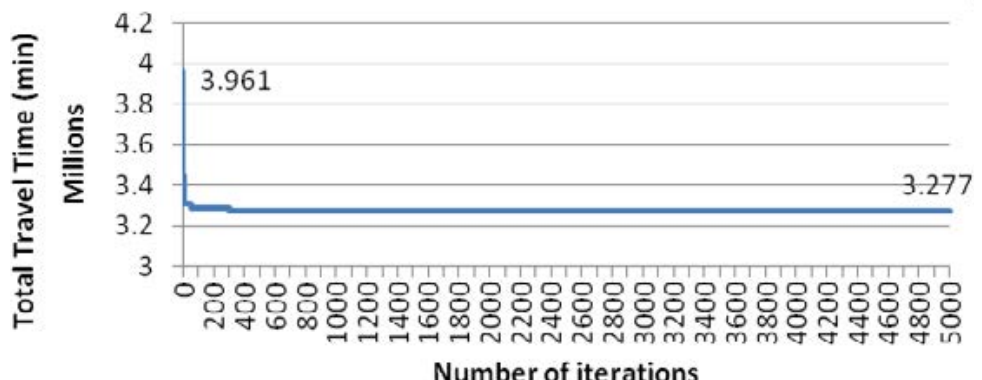

(b)

Fitness trends for Scenario II

(c)

Fitness trends for Scenario IIII

.2

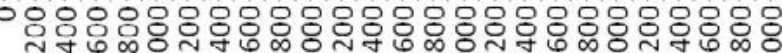

\section{Number of iterations}

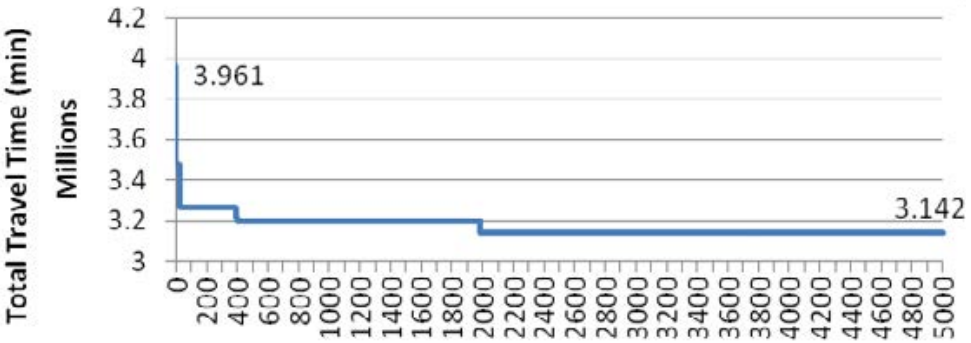

(d)

Fitness trends for Scenario IV 
nal all-stop operation. While in-vehicle travel time became about 20-26 percent shorter due to skipping stations, waiting time, transfer time, and additional access time became 24-38 percent longer.

Each train skipped 5-9 stations, which reduced 5-9 minutes (up to 8\%) of operating time. As mentioned, this model was built to minimize total travel time. If the model's objective was minimization of operating time or total cost, the model could reduce operating time more.

Although skip-stop operation is vulnerable to delays and disruptions, is complicated, can confuse passengers at the beginning stage of the service, it can reduce passenger total travel time and operator investment and operating costs.

This research concentrated on the modeling and solution processes. In the future, this research can be used in many different ways by changing input values to create feasible conditions for skip-stop operation. For example, this research categorized passengers into two groups-those who walk to stations and those who ride to stations. In the future, research could be conducted to determine if skip-stop operation is more suitable for a walking-oriented environment or a driving-oriented environment. The minimum number of stations and the minimum average trip length for the feasible skip-stop operation could be defined as well. In addition, research could determine the difference between the results of skip-stop operation with total cost minimization and with passenger travel time minimization.

\section{Acknowledgments}

This research was funded by the National Transportation Center at Morgan State University and supported by a National Research Foundation of Korea grant funded by the Korea government (MSIP) (NRF-2010-0029446). The authors express their deepest appreciation to Dr. Vukan R. Vuchic, emeritus professor at the University of Pennsylvania, for inspiring this research.

\section{References}

Goldberg, D. E. 1989. Genetic Algorithms in Search, Optimization, and Machine Learning. Addison-Wesley Pub. Co., Reading, MA.

Jong, Jyh-Cherng. 1998. Optimizing highway alignment with Genetic Algorithm. Ph.D. dissertation, University of Maryland at College Park. 
Jong, Kenneth Du. 1998. Learning with Genetic Algorithm: An Overview. Kluwer Academic Publishers.

Kittelson \& Associates. 2003. Transit Capacity and Quality of Service Manual, 2nd Ed. National Research Council, Transportation Research Board, Washington DC.

Niu, H. 2011. Determination of skip-stop scheduling for a congested transit line by bilevel Genetic Algorithm. International Journal of Computational Intelligence Systems 4(6): 1158-1167.

Suh, W., K. S. Chon, and S. M. Rhee. 2007. Effect of skip-stop policy of a Korean subway system. Transportation Research Record 1793: 33-39.

Vuchic, Vukan R. 2005. Urban Transit: Operations, Planning, and Economics. John Wiley \& Sons, Inc.

Vuhic, Vukan R. 2007. Urban Transit: Systems and Technology. John Wiley \& Sons, Inc.

Zheng, L., R. Song, S. He, and H. Li. 2009. Optimization model and algorithm of skipstop strategy for urban rail transit. Journal of the China Railway Society 31(6).

\section{About the Authors}

Young-Jae Lee, Ph.D. (YoungJae.Lee@morgan.edu) is an Associate Professor in the Department of Transportation and Urban Infrastructure Studies at Morgan State University in Baltimore, Maryland. He received a B.S. and M.S. at Seoul National University in Korea and another M.S. and Ph.D. from the University of Pennsylvania with his research for optimizing a transit network design problem. His main focus has been improvement of transit systems, and he has conducted different types of research projects and published papers on network design, operational efficiency, and ITS application for public transportation. Currently, he is conducting multiple projects for public transportation, including "Connected Vehicle Infrastructure Technology Application for Transit Systems" and "Advanced Transit Signal Priority Using Connected Vehicle Infrastructure Technology." He served as a voluntary reviewer for a new ITS ePrimer module for Public Transportation/Transit Management and is a Technical Advisory Group member for ITE/ITS Transit standard module development. He is a member of the TRB APO40 Automated Transit Systems Committee and an editorial board member of the Korean Society of Civil Engineering's KSCE Journal of Civil Engineering. 
SHAGHAYEGH SHARIAT (Shariats@PBworld.com) is a transportation planner with Parsons Brinckerhoff in Seattle, Washington, and a doctoral candidate in Transportation and Urban Infrastructure Studies at Morgan State University in Baltimore, Maryland. She received a B.Sc in Civil Engineering with a focus on surveying in 2003 from the University Tabriz, Iran, and an M.S. in Transportation and Highway Design Engineering in 2007 at the University of Putra Malaysia, Kuala Lumpur, Malaysia. Her research interests are sustainable roadway/highway design models and optimization.

KefChoo CHOI, PH.D. (keechoo@ajou.ac.kr) is a professor in the Department of Transportation Engineering and an Associate Dean of the Graduate School of ITS at Ajou University in Suwon, Korea. He received a B.S. and M.S. in Civil Engineering from Seoul National University, a Ph.D. in Regional Transportation Planning from the University of Illinois at Urbana-Champaign, and a second Ph.D. in Civil and Environment Engineering from the University of Wisconsin at Madison. He founded a transportation journal and is currently working as managing editor of the International Journal of Sustainable Transportation. He also serves on the editorial boards of the Journal of Intelligent Transportation Systems and Transportmetrika Part B. His research interests are transportation planning, transportation safety modeling, sustainable transportation system implementation, and ITS. 